\title{
PHASE LOOP BANDWITH MEASUREMENTS ON THE ADVANCED PHOTON SOURCE 352-MHZ RF SYSTEMS
}

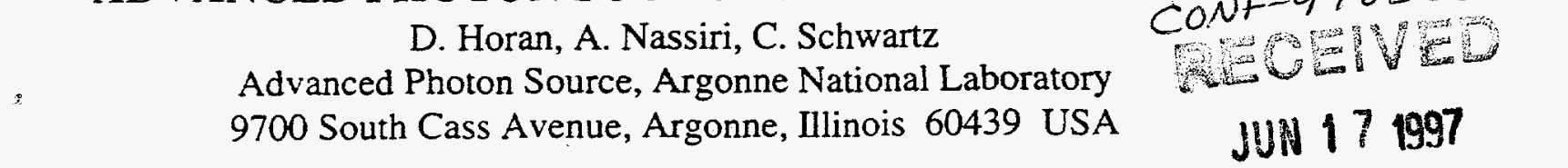

\section{Abstract}

Phase loop bandwidth tests were performed on the Advanced Photon Source storage ring $352-\mathrm{MHz}$ if systems. These measurements were made using the HP3563A Control Systems Analyzer, with the rf systems running at 30 kilowatts into each of the storage ring cavities, without stored beam. An electronic phase shifter was used to inject approximately 14 degrees of stimulated phase shift into the low-level if system, which produced measurable response voltage in the feedback loops without upsetting normal if system operation. With the PD (proportionalintegral-differential) amplifier settings at the values used during accelerator operation, the measurement data revealed that the 3-dB response for the cavity sum and klystron power-phase loops is approximately $7 \mathrm{kHz}$ and 45 $\mathrm{kHz}$, respectively, with the cavities the primary bandwidthlimiting factor in the cavity-sum loop. Data were taken at various PID settings until the loops became unstable. Crosstalk between the two phase loops was measured.

\section{RF SYSTEM OVERVIEW}

The Advanced Photon Source has four identical 1megawatt klystron if systems dedicated to supplying power to 16 storage-ring single-cell cavities, arranged four cavities to a sector. The present operational mode uses two klystrons, each supplying power to eight cavities (two sectors, four cavities per sector) through a series of $3-\mathrm{dB}$ hybrids to divide the klystron if output by eight.

A single-line schematic of an APS if system is shown in Figure 1. Two phase control loops, one nested within the other, are used to stabilize the phase of the rf voltage in the cavities. The power-phase loop closes around he klystron, 100-watt driver amplifier, and klystron driver AGC loop. This loop removes phase noise caused by the ripple on the DC output of the klystron high-voltage power supply (HVPS) and changes in if modulator output due to the AGC loop action. The cavity-sum phase loop closes around the entire of station and maintains phase stability between the input if source signal and the cavity sum signal. which is composed of the vector sum of the field probe outputs of all eight cavities (two sectors combined) fed by the klystron. This loop removes remaining HVPS rippleinduced phase shift in the klystron output and any phase noise generated in the cavity. Measurements have shown that the combined performance of the two phase control loops reduces the phase jitter in the cavity rf signal to less than 1 degree peak-to-peak.

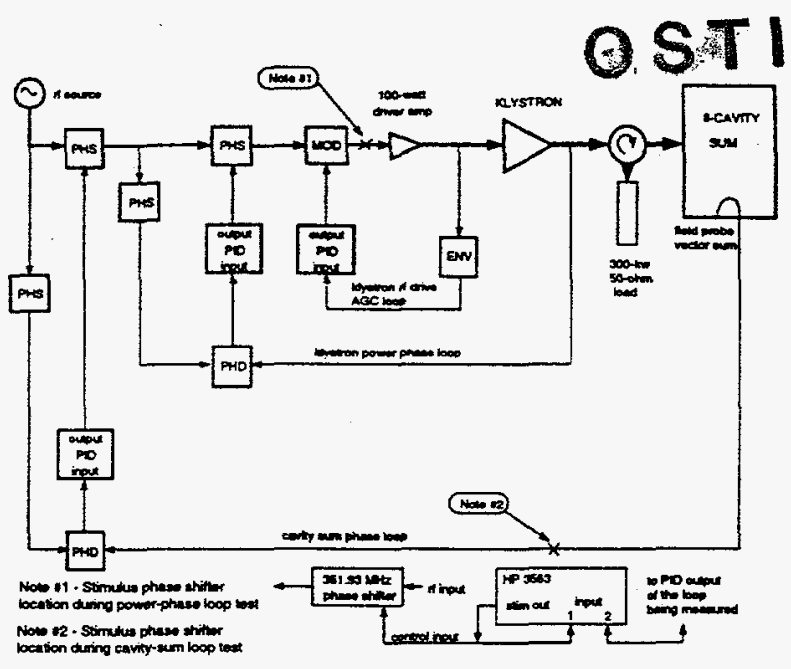

Figure 1: The rf system layout and closed-loop response measurement setup.

Each of the storage ring cavities is tuned by a motordriven piston tuner that is controlled by a phase loop around the cavity, comparing the phase of cavity forward power to the phase of the cavity field probe output signal. The phase error signal is amplified and conditioned by a PID controller that supplies an input signal to the tuner drive stepping motor, moving the tuner piston in the direction of cavity resonance. The low-level if system utilized for cavity tuning is physically located a distance from the klystron low-level rf system and operates totally independent of the klystron system.

The low-level rf hardware is packaged in VXI modules which house analog $\mathrm{rf}$ modules digitally interfaced to the APS EPICS (Experimental Physics and Industrial Control System) [1] system for remote control and monitor functions. The 100-watt klystron driver amplifier is located in the same equipment rack as the klystron lowlevel if VXI crate, all of which is located approximately 30 feet from the klystron.

\section{MEASUREMENT SETUP}

Initial closed-loop phase loop response measurements were performed on the RF\#1 and RF\#2 stations in the fall of 1996, and the test results showed little difference in performance between them. Similar testing at the RF\#4 station indicated performance very close to the other stations. Since it was the most mature system of the three at that time, RF\#4 was selected as the subject of extensive response tests. Two basic types of measurements were made: real-time, closed-loop response with the stimulus

The submitted manuscript has been created by the University of Chicago as Operator of Argonne National Laboratory ("Argonne") under Contract No. W-31-109-ENG-38 with the U.S. Deparment of Energy. The U.S. Government retains for itself, and others acting on its behalf, a paid-up, nonexclusive, irtevocabie worldwide license in said aricle to reproduce, prepare derivative works. distribute copies to the public, and perform publicly and display publicly, by or on behalf of the Government. 


\section{DISCLAIMER}

This report was prepared as an account of work sponsored by an agency of the United States Government. Neither the United States Government nor any agency thereof, nor any of their employees, make any warranty, express or implied, or assumes any legal liability or responsibility for the accuracy, completeness, or usefulness of any information, apparatus, product, or process disclosed, or represents that its use would not infringe privately owned rights. Reference herein to any specific commercial product, process, or service by trade name, trademark, manufacturer, or otherwise does not necessarily constitute or imply its endorsement, recommendation, or favoring by the United States Government or any agency thereof. The views and opinions of authors expressed herein do not necessarily state or reflect those of the United States Government or any agency thereof. 


\section{DISCLAMIER}

Portions of this docament may be illegible in electronic image produetc. Images are produced from the best available original document. 
injected in the of domain and open-loop characteristics with the loops closed using a summing junction for injection of the stimulus signal into the PID controller output. During both measurements, the if system under test was operating at approximately 30 -kilowatts per cavity, with the klystron operating at $85 \mathrm{kV}$ and 10.0 amps of beam current. No stored beam was present in the machine.

Closed-loop measurements of the phase loop frequency response were made on our RF $\$ 4$ station using a direct method of phase noise injection using an electronic If phase shifter, an even wavelength long, inserted into the If system at points within each phase loop (see Figure 1). These measurements were made at different PID gain settings to determine the maximum loop gain allowable for stable if system operation. The stimulus if phase shifter was driven with a swept-frequency sinusoidal $\mathrm{AC}$ control signal, a 1-volt peak AC component superimposed on a +1 -volt offset, to produce if phase stimulation within the loop. The +1 -volt offset was necessary for this test, as the phase shifter response becomes very nonlinear with a negative-going control voltage. The phase shifter has a frequency response of $+/-1.6 \mathrm{~dB}$ from $100 \mathrm{~Hz}$ to $100 \mathrm{kHz}$. This control voltage produced approximately 14 degrees peak-to-peak of $\mathrm{rf}$ phase shift at $351.93 \mathrm{MHz}$. The output amplitude of the PID amplifier in each phase loop was then measured to determine the loop response and the amount of crosstalk between the loops. The HP3563 Control Systems Analyzer was used to generate the stimulus signal that drove the rf phase shifter and also to measure the PID output signal amplitude relative to the stimulus signal.

Making true open-loop measurements of these phase loops is impossible. The DC gain of the PID amplifier is immense, and breaking the loop causes the PID output to saturate at one of its output limits. Measurements of openloop characteristics with the loop closed were made by using a unity-gain summing junction for injection of the stimulus signal into the PID amplifier ourput, while measuring the output amplitude of the PID amplifier at a point before the summing junction [2]. This measurement setup is detailed in the partial system schematic shown in Figure 2. These measurements were made using two different methods. swept Fourier transform (SFT) and fast Fourier transform (FFT). In the SFT tests, the stimulus signal consisted of a $500-\mathrm{mV}$ peak sine-wave slowly swept in frequency from $100 \mathrm{~Hz}$ to $100 \mathrm{kHz}$. In the FFT tests, the stimulus signal was a $500-\mathrm{mV}$ peak broadband noise source. Both stimulus signals were generated by the control system analyzer. The PID amplifier gains were set to unity $(P=1 . I=1, D=1)$ for these tests.

\section{LOOP RESPONSE DATA}

The closed-loop response tests were performed with the PID amplifier $A C$ gains set at the normal values for accelerator operation (see Figures 3(a) and (b)). The power-phase loop was tested with the PID gain set to 4 . and exhibits a response that is essentially tiat within $3 \mathrm{~dB}$ to approximately $10 \mathrm{kHz}$. It has an apparent gain margin of
$16 \mathrm{~dB}$. The cavity-sum phase loop was tested with the PID P-gain set to 1.56; it has flat response to $3 \mathrm{kHz}$ and is down $20 \mathrm{~dB}$ at $10 \mathrm{kHz}$, with an apparent gain margin of over 28 $\mathrm{dB}$. The more narrow response of the cavity sum loop is due to the effect of the $7-\mathrm{kHz}$ bandwidth of the storage ring cavities on the field probe signals.

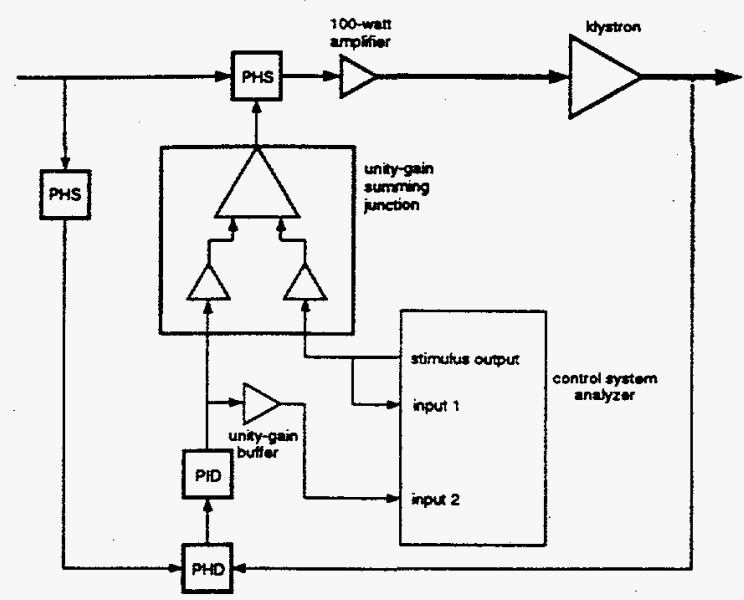

Figure 2: Setup for measuring open-loop characteristics.
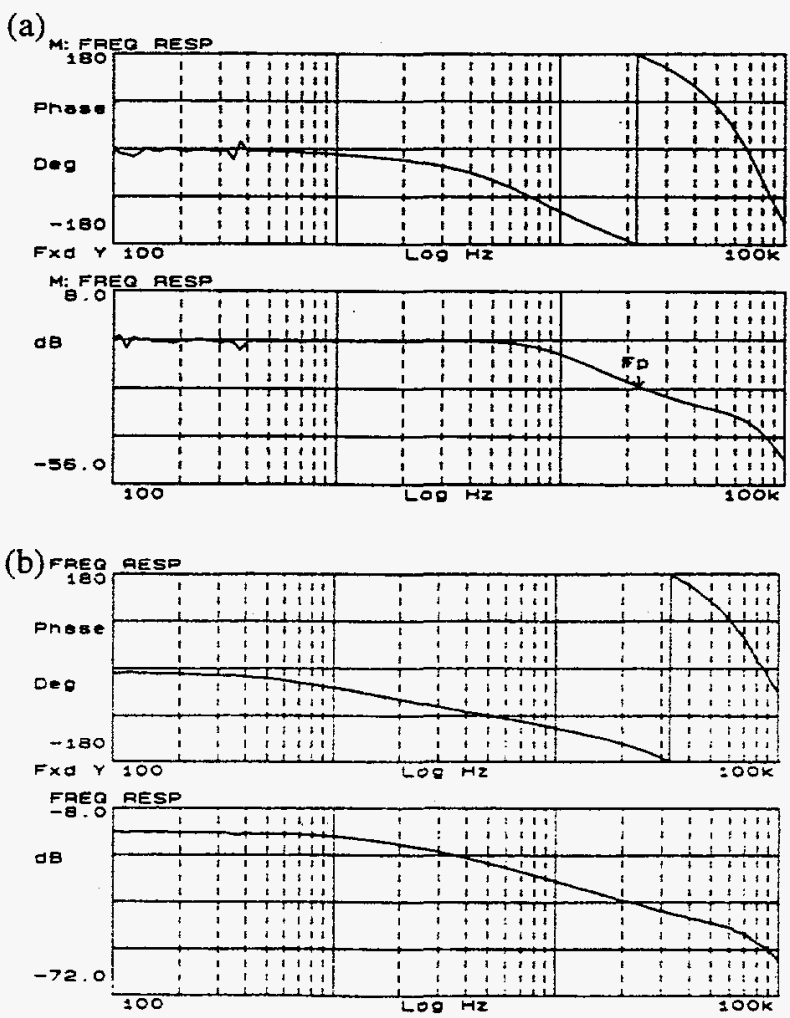

Figure 3: (a) Power-phase closed-loop response test-PID GAIN = 4; (b) cavity-sum phase closedloop response test - PID GAIN $=1.56$. 

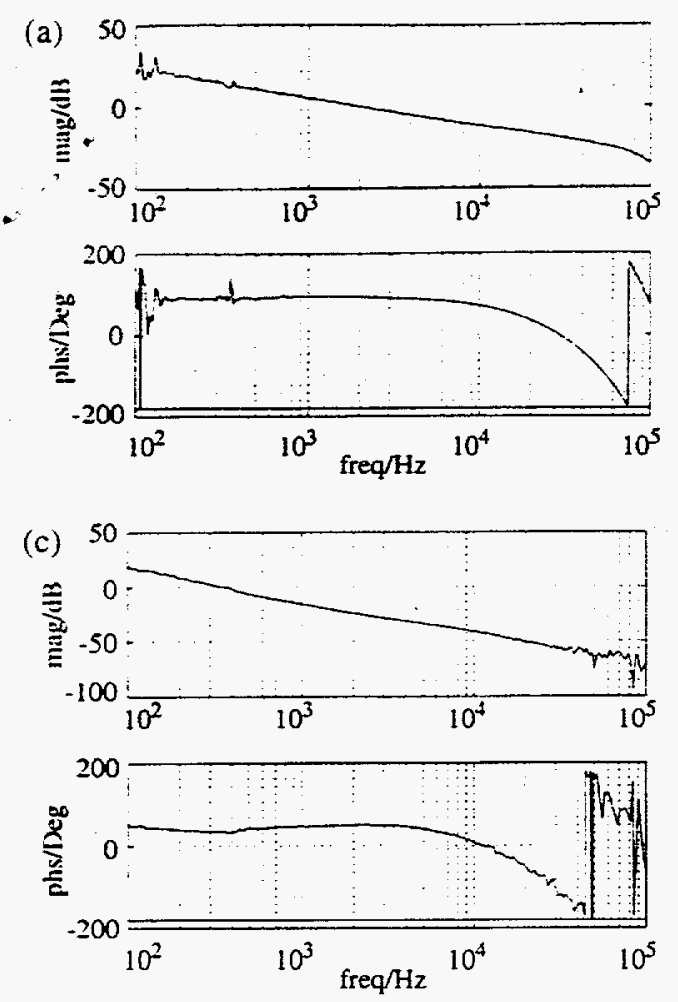

(b)
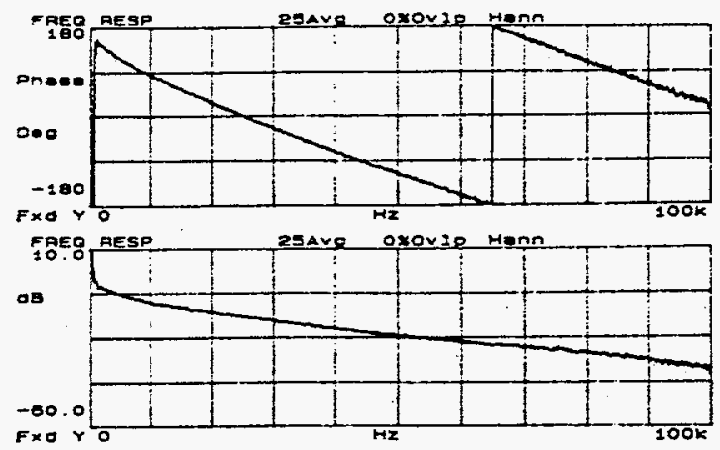

(d)
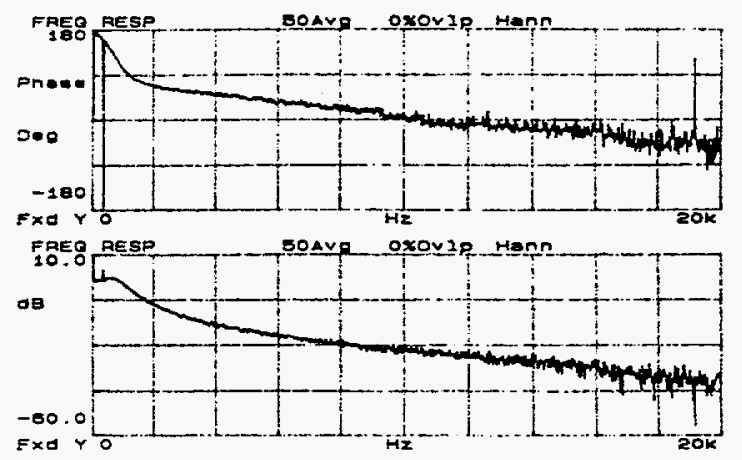

Figure 4: (a) Power-phase loop open-loop characteristics using SFT method; (b) power-phase loop open-loop characteristics using FFT method; (c) cavity-sum phase loop open-loop characteristics using SFT method;

(d) cavity-sum phase loop open-loop characteristics using FFT method.

The open-loop characteristic data are shown in Figures 4 (a) through (d). These measurements were made with the PID amplifier AC gains set to unity in both loops. The SFT tests on the power-phase loop indicate gain and phase margins of approximately $25 \mathrm{~dB}$ and 270 degrees, respectively. The conclusions are closely matched by data obtained using the FFT method. The SFT tests on the cavity-sum loop indicate gain and phase margins of approximately $75 \mathrm{~dB}$ and 270 degrees, respectively, again with the cavity bandwidth increasing the gain margin significantly. The FFT tests on the cavity-sum loop were performed from $\mathrm{DC}$ to $20 \mathrm{kHz}$ only, as the signal level back from the cavities at test frequencies greater than $20 \mathrm{kHz}$ was very low. Test results here indicate that in the operating bandwidth of the field probe signal, there is no evidence of 180 degree phase shift to invite instability. The fluctuations in all of the data at 60,120 , and $360 \mathrm{~Hz}$ are due to the loops actively working to reduce phase shift caused by power supply ripple on the klystron cathode voltage, resulting in distortions in the data at these frequencies.

Power-phase to cavity-sum crosstalk was measured at $-26 \mathrm{~dB}$ between $100 \mathrm{~Hz}$ and $1 \mathrm{kHz}$. rising to $-16 \mathrm{~dB}$ at 5 $\mathrm{kHz}$ and falling to $-42 \mathrm{~dB}$ at $100 \mathrm{kHz}$. Cavity-sum to power-phase crosstalk was found to be between $-50 \mathrm{~dB}$ and $-60 \mathrm{~dB}$ down from $100 \mathrm{~Hz}$ to $100 \mathrm{kHz}$. There measurements were made at the RF\# $l$ station. with the PID AC gains set at the normal operating values mentioned.

\section{CONCLUSION}

These response measurements show that if system operation with phase loop PID amplifier P-gains of 1.56 and 4 provides adequate performance with comfortable gain and phase margins at a storage ring current of 100 $\mathrm{mA}$. Crosstalk between the loops is within acceptable limits and does not contribute to performance degradation.

\section{ACKNOWLEDGMENTS}

I would like to acknowledge the efforts of Mike Phelan and Bill Yoder in constructing the summing junction amplifier used for these tests, as well as Don Voss and Ernie Cherbak for their assistance during the tests. This work was supported by the U.S. Department of Energy, Office of Basic Energy Sciences, under Contract No. W31-109-ENG-38.

\section{REFERENCES}

[1] L.R. Dalesio, M.R. Kaimer, A. J. Kozubai, "EPICS Architecture." Proc. of ICALEPCS '91. Tsukuba-Shi, Ibaraki, Japan, KEK Proceedings 92-15, pp. 278-282, December 1992.

[2] "Control System Measurement Fundamentals Using Dynamic Signal Analyzers." Hewlett-Packard Application Note 243-6. 